\title{
Application of Fuzzy Adaptive Tuning PID Control in the Boiler Deaerator System
}

\author{
Nina Zhou and Li Wang \\ Baoji University of Arts \& Sciences, Baoji, Shaanxi, 721013 \\ ndd0828@126.com
}

\begin{abstract}
Boiler deaerator system was introduced in this paper, the dynamic characteristics of the system was analyzed, the transfer function of the system was obtained.According to the system time's delay and non-linearity, the fuzzy adaptive tuning PID control strategy was formulated, the system simulation was completed by MATLAB . Experimental simulation results of MATLAB show that the fuzzy adaptive tuning PID control can complete system control better, and obtain better dynamic and static performance.
\end{abstract}

Keywords: Non-linearity, fuzzy adaptive, simulation

\section{Introduction}

Boiler deaerator are mostly used in heating and power generation system. The deaerator is mainly used for removal oxygen and carbon dioxide and other non-condensing gas in boiler feed water, the boiler feed water is heated to their the saturation temperature under the deaerator device operating pressure, the surface area of the water is increased as large as possible and the surface tension will be reduced, and the gas escaping from water is discharged in time, the unbalanced pressure difference is also increased, so, the standard saturated oxygen water will be obtained, which will be storage in the deaerator water tank It is readily available for the boiler and it can ensure the safe operation of the boiler.

Many foreign experts and scholars had conducted an in-depth study on the deaerating System. The view of Feng Yu Wen were :A high level of oxygen in boiler supply water would lead to oxidation corrosion of the boiler tubes. In Soil-field, a combining measure of physical and chemical methods were adopted to improve deaerator technology. The deaeration system consists of water ring vacuum pump, deaeration tank, booster pump, circulating tank, etc. First softened water processed by softener would flow through 80 mesh stainless steel screen filter. Then in high vacuum deaeration tank, the water will be ejected in a spray due to the eddying flow of the nozzles and size of the droplet can reach 30 micrometer [1]. The following results were Ruofei Guo's : For the deaerator non-linear, time-varying large delay, and model features dual use of a class of adaptive predictive functional control algorithm, the use of dual control to adjust the existing adaptive control law to obtain information on unknown parameters and to effectively suppress the strong coupling caused by controlling the amount of volatility [2].Lei jinli proposed fuzzy PID control to the boiler deaerator system [3].In this paper, the deaerator of the power plant is the controlled object, the fuzzy adaptive tuning PID control is proposed with the online adjusted function, it can handle the system's uncertainty, non-linearity and time variability.

\section{2 .Confirmation of Control Strategy}

Thermal deaerator is mainly used to remove oxygen and carbon dioxide and other noncondensable gases in boiler feed-water. Oxygen could combine with a lot of non-metallic substance directly because of its activity, furthermore, this direct combination is applicable 
to most metals (gold, silver, except a few metal platinum, etc). The stable or precipitate are usually formed after this combination is accomplished, and oxygen in oxide would not combine with metals any more [4-15]. In another word, what causes a corrosion effect is the dissolved oxygen in water, which should be eliminated.

Since the saturated content of various gases differs from one another under different pressures and temperatures. The study shows that pressure at the interface of water and vapor is the saturated vapor pressure when water is heated to be boiled, meanwhile, the solubility of vapor in water should be equaled as zero. This characteristic is used by thermal deaeration. The principle of deoxidation is: boiler feed water is heated to boiling point, with the reduction of oxygen solubility and constant escape of oxygen in the water, then the oxygen produced above water and the vapor would be excluded together. This method could be applied to get rid of some more gases in water (including $\mathrm{CO} 2$ in free state, N2). Besides, make sure that the water is heated to boiling temperature under working pressure of oxygen, usually $104{ }^{\circ} \mathrm{C}$. Both the amount of salt and other dissolved gases would not be increased after deoxidation, which brings a relatively simple controllability and a stable operating status. Therefore, this paper intends to control the temperature of deaerator in order to achieve the goal of removal of dissolved oxygen in water boilers and safe operation.

Since the boiler deaerator is a complex dynamic system, except for its nonlinear and hysteresis feature, a deep coupling relationship existing among parameters. In consequence, it is difficult to normal control theory to obtain preferable control effect. The fuzzy adaptive tuning PID control strategy would not rely on mathematical model, dealing with nonlinear problems with a favorable robustness and adaptive feature. Therefore, this paper applies the fuzzy adaptive tuning PID control strategy to dominate the temperature of deoxidation system.

\section{Determination of Dynamic Characteristics of Controlled Object}

After a detailed analysis of the thermal deaerator,the transfer function of the system can be considered as that it is composed of delay model and multiple non-cycle model.The transfer function [4] is when the $\mathrm{W}_{\mathrm{p}}(\mathrm{s})=\mathrm{Ke}^{-\mathrm{ss}} /(\mathrm{Ts}+1)^{\mathrm{n}}$ control variable $\mathrm{u}(\mathrm{t})$ is the unit step signal,

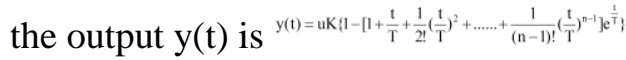

For different $n$, the results of the different $y(t)$ under different $t / T$ values are shown in Table 1.

Table 1. The Value of $y(t)$ for Different $N$ and $T / T$

\begin{tabular}{|c|c|c|c|c|c|c|c|c|}
\hline \multirow{2}{*}{$\mathrm{n}$} & \multicolumn{9}{|c|}{$\mathrm{t} / \mathrm{T}$} \\
\cline { 2 - 9 } & 0.5 & 1 & 2 & 3 & 4 & 5 & 6 & 7 \\
\hline 1 & 0.393 & 0.632 & 0.865 & 0.95 & 0.982 & 0.953 & & \\
\hline 2 & 0.09 & 0.264 & 0.594 & 0.801 & 0.908 & 0.96 & 0.983 & 0.993 \\
\hline 3 & 0.014 & 0.083 & 0.323 & 0.577 & 0.762 & 0.875 & 0.938 & 0.97 \\
\hline 4 & & 0.019 & 0.143 & 0.353 & 0.566 & 0.735 & 0.849 & 0.918 \\
\hline 5 & & & 0.053 & 0.185 & 0.371 & 0.56 & 0.715 & 0.827 \\
\hline
\end{tabular}

The system is open loop state, the controller is placed in the manual, the output voltage is changed by step, the output current of the transmitter is recorded, and the step response curve can be obtained. For different order of $\mathrm{n}$, the results are listed in Table 2:

Table 2. The Table of Characteristic Parameter Value

\begin{tabular}{|l|c|c|c|c|c|c|c|c|}
\hline characteristi & \multicolumn{9}{|c|}{$\mathrm{n}$} \\
\cline { 2 - 9 } c parameter & 2 & 3 & 4 & 5 & 6 & 7 & 8 & 9 \\
\hline $\mathrm{y} 0 /(\mathrm{uK})$ & 0.264 & 0.323 & 0.353 & 0.371 & 0.384 & 0.394 & 0.401 & 0.408 \\
\hline
\end{tabular}




\begin{tabular}{|c|c|c|c|c|c|c|c|c|}
\hline$\tau / \mathrm{Ta}$ & 0.104 & 0.218 & 0.319 & 0.410 & 0.493 & 0.570 & 0.642 & 0.709 \\
\hline $\mathrm{T} / \mathrm{Ta}$ & 0.368 & 0.271 & 0.224 & 0.195 & 0.176 & 0.161 & 0.143 & 0.140 \\
\hline $\mathrm{T} / \tau$ & 3.55 & 1.24 & 0.702 & 0.476 & 0.282 & 0.282 & 0.232 & 0.197 \\
\hline $\mathrm{T} / \mathrm{t} 0$ & 1.00 & 0.500 & 0.333 & 0.250 & 0.200 & 0.167 & 0.143 & 0.125 \\
\hline $\mathrm{T} / \mathrm{t} 1$ & 0.333 & 0.222 & 0.170 & 0.139 & 0.118 & 0.1023 & 0.0908 & 0.0817 \\
\hline
\end{tabular}

According to the calculation, the approximation of characteristic parameter can be gotten generalized time constant $\mathrm{Ta}=17 \mathrm{~s}$, amplification factor $\mathrm{K}=9.4$, inflection point $\mathrm{t} 0=9.2 \mathrm{~s}$, inflection value yo $=3.04$, delay time $\tau=4$ s, so y0 $(\mathrm{uK})=3.04 / 9.4=0.323$ is known by Table 2 , that is $\mathrm{n}=3, \mathrm{~T} / \mathrm{Ta}=0.271, \mathrm{~T}=4.6 \mathrm{~s}$ is counted.The transfer function of the deaerator system is $G(s)=\frac{9.4}{(4.6 s+1)^{3}} e^{-4 s}$

\section{4 .The Design of Deaerator Temperature Control [16-20]}

Basic task of the deaerator temperature control in power plant boiler is keep the deaerator temperature in $104 \pm 3^{\circ} \mathrm{C}$ under the condition of load wide fluctuations and feed water flow disturbance and other factors in order to assure the boiler's safety and stable operation.

According to the function, the system block diagram is shown in figure 1.

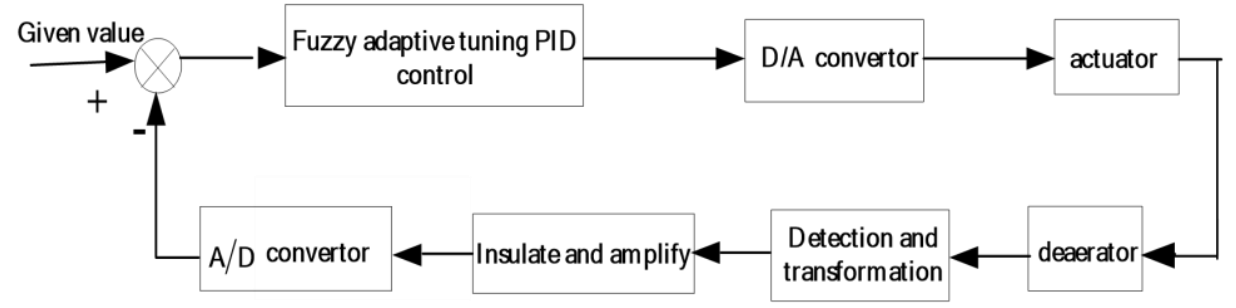

Figure 1. The System Block Diagram of the Deaerator Temperature Control

Deaerator temperature is detected by the temperature sensor and converted into 4 $20 \mathrm{~mA}$ standard current signal, the current signal will be converted into a $0 \sim 5 \mathrm{~V}$ voltage signal through the voltage conversion device, then the signal enters into analog input channel of the micro-controller ,A/D conversion turns the analog signal into digital signal, the digital signal is as a input for the fuzzy PID controller.The comparison is made between the converter value and the given value,so the temperature error and the change rate of temperature error are counted.The output is calculated by fuzzy adaptive PID control strategy. D/A controller will convert the output for the driving actuator so as to keep the deaerator temperature keeping in the range of the given value.

\section{5 .The Design of Fuzzy Adaptive Tuning PID Controller}

Normal PID controller is the base of fuzzy adaptive tuning PID controller. The fuzzy inference theory is used to adjust three parameters of the PID online based on according to different e and ec. The control system has two parts, that is fuzzy inference part and the conventional PID part, the structure diagram is shown in Figure 2.The software flow chart is shown in Figure 3. 


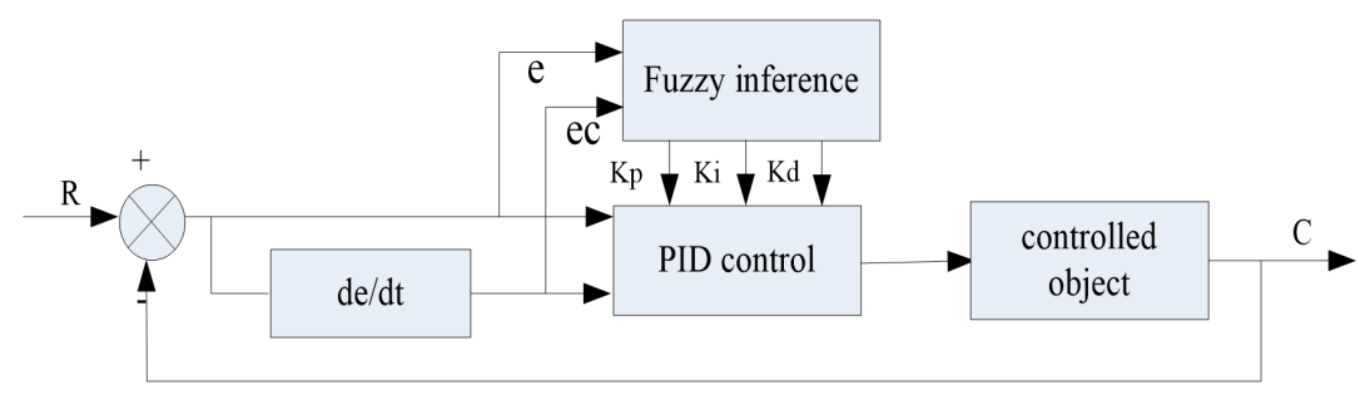

Figure 2. The Structure Diagram Of Fuzzy Adaptive Tuning PID Controller

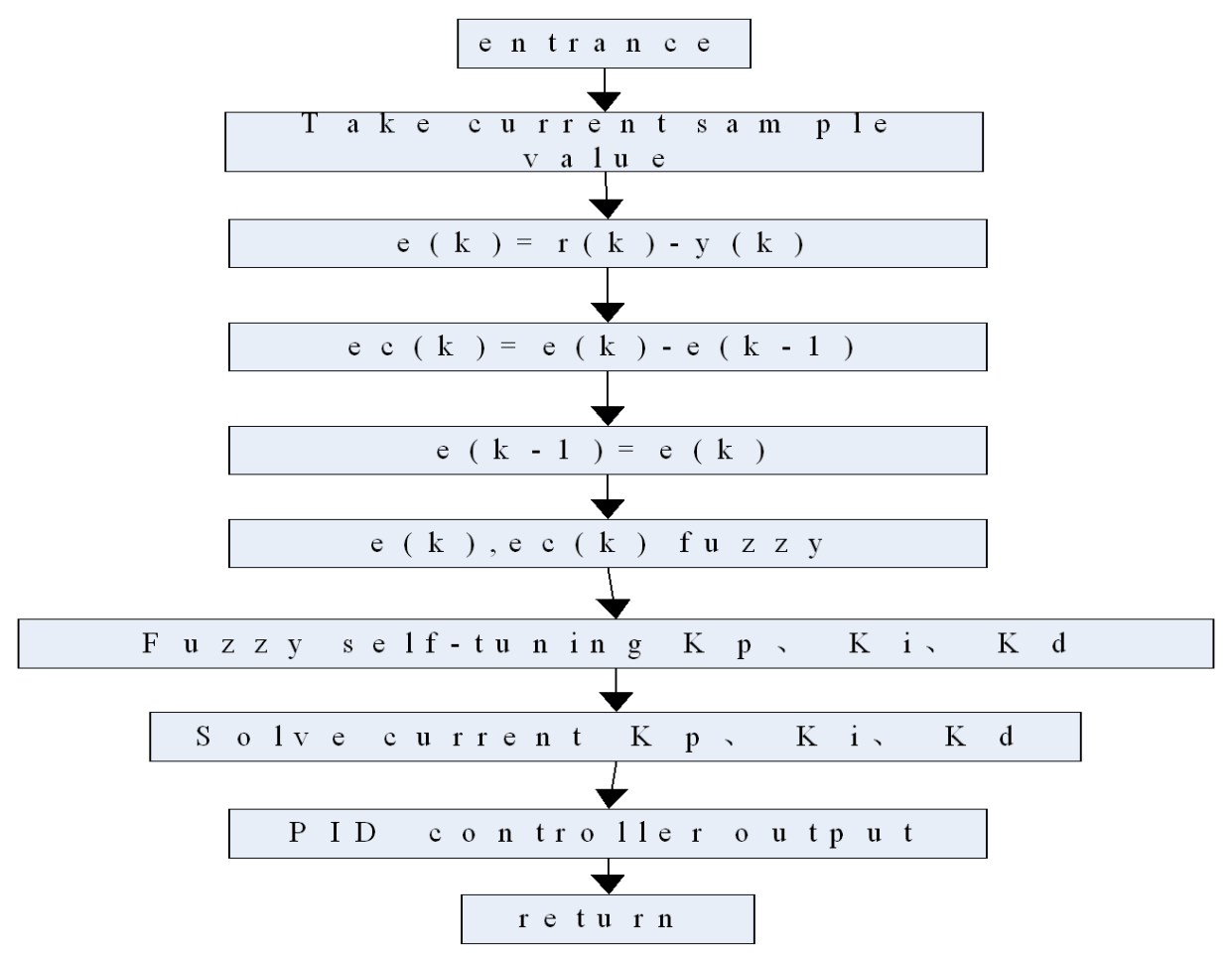

Figure 3. The Software Flow Chart of Fuzzy Adaptive Tuning PID Control

Error e and the change rate of error ec are inputs as shown in Fig.2,the fuzzy relationship between the three parameters of PID, ec and e is found out,e and ec is detecting when running.Online adjusting and regulation are done by using fuzzy inference,this makes the plant with good dynamic and static characteristic.

According to the actual working condition of the deaerator, considering the sensor error, the basic domain of temperature error e is $\left[-3^{\circ} \mathrm{C}, 3^{\circ} \mathrm{C}\right]$, the basic domain of ec is taken as $[-$ $\left.1^{\circ} \mathrm{C},+1^{\circ} \mathrm{C}\right]$.

According to tuning results of the deaerator coefficient, parameters can be determined as follows. $\Delta \mathrm{Kp}$ is on the basic domain [-6 6].The basic domain $\Delta \mathrm{Ki}$ is [-0.6 0.6].] $\Delta \mathrm{Kd}$ is on basic domain [-390 390].

Suggesting error e and the change of error ec and the output variable $\Delta \mathrm{Kp}, \Delta \mathrm{Ki}, \Delta \mathrm{Kd}$ of domain quantization are all 13 grades: $\{-6,-5,-4,-3,-2,-1,0,+1,+2,+3,+4$ $,+5,+6\}$.

The quantitative factors of temperature deviation and deviation change can be calculated by the basic domain and the quantitative level of the input variables. 


$$
\mathrm{Ke}=6 / 3=2 \quad \mathrm{Kec}=6 / 1=6
$$

The fuzzy adaptive PID control strategy requires that both of the input and output variables are fuzzy, however, current variables are accurate. Hence the fuzzification needs to be carried out initially. Selecting 7 words to describe the status of input and output variables, namely: \{negative big, negative middle, negative small, zero, positive small, positive middle, positive big $\}$, with the acronym of: $\{\mathrm{NB}, \mathrm{NM}, \mathrm{NS}, \mathrm{ZE}, \mathrm{PS}, \mathrm{PM}, \mathrm{PB}\}$. The next step is to determine the shape of the membership function curve of the fuzzy subset, then discretize the curve to obtain the membership degree in several points. Therefore, a fuzzy subset of the corresponding fuzzy variables is built. Due to the various shapes of the membership function curves leads to different control characteristics. The shape of function curve which is pointed on the upper end owns a higher resolution and control sensitivity; On the contrary, the shape that is as gentle as the control characteristic, implying that the system is stable. Consequently, when the membership function of the fuzzy variable sets is selected, the region with larger errors should adopt a lower resolution, and meanwhile, the region with smaller errors or close to zero should adopt a higher resolution.

This paper applies a triangle membership function with a higher sensitivity in the design of the membership function of error e , the change rate of the error ec and output variables $\mathrm{u}$.According to the operation experience and the experimental analysis, the temperature error e, the temperature error rate ec and the control of the $u$ membership functions are shown in Table 3, Table4,Table5 respectively.

Table 3. Membership Function Assignment Table of E

\begin{tabular}{llllllllllllll}
\hline $\mathrm{e}$ \\
$\mu E$ \\
$\mathrm{E}$
\end{tabular}


Table 4. Membership Function Assignment Table of EC

\begin{tabular}{|c|c|c|c|c|c|c|c|c|c|c|c|c|c|}
\hline $\begin{array}{l}\mu E \\
\mathrm{ec} \\
\mathrm{EC}\end{array}$ & -6 & -5 & -4 & -3 & -2 & -1 & 0 & 1 & 2 & 3 & 4 & 5 & 6 \\
\hline NB & 1 & 0.7 & 0.3 & 0.1 & 0 & 0 & 0 & 0 & 0 & 0 & 0 & 0 & 0 \\
\hline NM & 0.1 & 0.6 & 1 & 0.6 & 0.1 & 0 & 0 & 0 & 0 & 0 & 0 & 0 & 0 \\
\hline NS & 0 & 0 & 0.1 & 0.6 & 1 & 0.8 & 0 & 0 & 0 & 0 & 0 & 0 & 0 \\
\hline $\mathrm{ZO}$ & 0 & 0 & 0 & 0 & 0.1 & 0.4 & 1 & 0.4 & 0.1 & 0 & 0 & 0 & 0 \\
\hline PS & 0 & 0 & 0 & 0 & 0 & 0 & 0 & 0.8 & 1 & 0.6 & 0.1 & 0 & 0 \\
\hline $\mathrm{PM}$ & 0 & 0 & 0 & 0 & 0 & 0 & 0 & 0 & 0.1 & 0.6 & 1 & 0.6 & 0.1 \\
\hline PB & 0 & 0 & 0 & 0 & 0 & 0 & 0 & 0 & 0 & 0.1 & 0.3 & 0.7 & 1 \\
\hline
\end{tabular}

Table 5. Membership Function Assignment Table of $U$

\begin{tabular}{llllllllllllllll}
\hline & & & & & & & & & & \\
$\mathrm{u}$ & -6 & -5 & -4 & -3 & -2 & -1 & 0 & 1 & 2 & 3 & 4 & 5 & 6 & 7 \\
$\mathrm{U}$ & & & & & & & & & & & & & & \\
\hline $\mathrm{PB}$ & 0 & 0 & 0 & 0 & 0 & 0 & 0 & 0 & 0 & 0 & 0 & 0.1 & 0.3 & 0.7 & 1.0 \\
$\mathrm{PM}$ & 0 & 0 & 0 & 0 & 0 & 0 & 0 & 0 & 0 & 0.1 & 0.6 & 1.0 & 0.6 & 0.1 & 0 \\
$\mathrm{PS}$ & 0 & 0 & 0 & 0 & 0 & 0 & 0 & 0.3 & 1.0 & 0.7 & 0.3 & 0.1 & 0 & 0 & 0 \\
$\mathrm{O}$ & 0 & 0 & 0 & 0 & 0 & 0 & 0.5 & 1.0 & 0.5 & 0 & 0 & 0 & 0 & 0 & 0 \\
$\mathrm{NS}$ & 0 & 0 & 0 & 0.1 & 0.3 & 0.7 & 1.0 & 0.3 & 0 & 0 & 0 & 0 & 0 & 0 & 0 \\
$\mathrm{NM}$ & 0 & 0.1 & 0.6 & 1.0 & 0.6 & 0.1 & 0 & 0 & 0 & 0 & 0 & 0 & 0 & 0 & 0 \\
$\mathrm{NB}$ & 1.0 & 0.7 & 0.3 & 0.1 & 0 & 0 & 0 & 0 & 0 & 0 & 0 & 0 & 0 & 0 & 0 \\
\hline
\end{tabular}

The controller design with two inputs and three outputs is shown in Fig.4, Mamdani max-min deduction method is applied to the controller. 


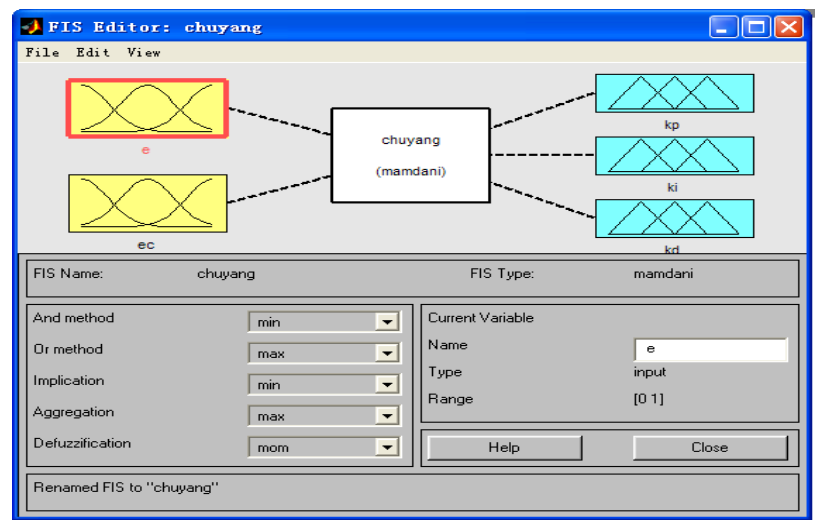

Figure 4. The Block Diagram Design

Consideration of system accuracy and time requirement, the output of controller obtains optimal dynamic and steady state features. When e is bigger enough, Kp should be bigger and $\mathrm{Kd}$ should be smaller in order to achieve rapid responding time and to avoid the starting e value becoming bigger instantly, which may cause different over-saturation and make the control exceed allowance extent.At the same time integral effect should be limited and $\mathrm{Ki}=0$ should be generally made in order to avoid bigger overshoot because of integral over-saturation. If the change ratio of error is positive, it indicates that the error has decrease trend, so the control variable should be smaller.

And so on,the system fuzzy control rules are as Table 6 according to control strategy above.

The controlling principles in MATLAB Simulink model are shown in Figure 5.

Table 6. The Controlling Rules Table

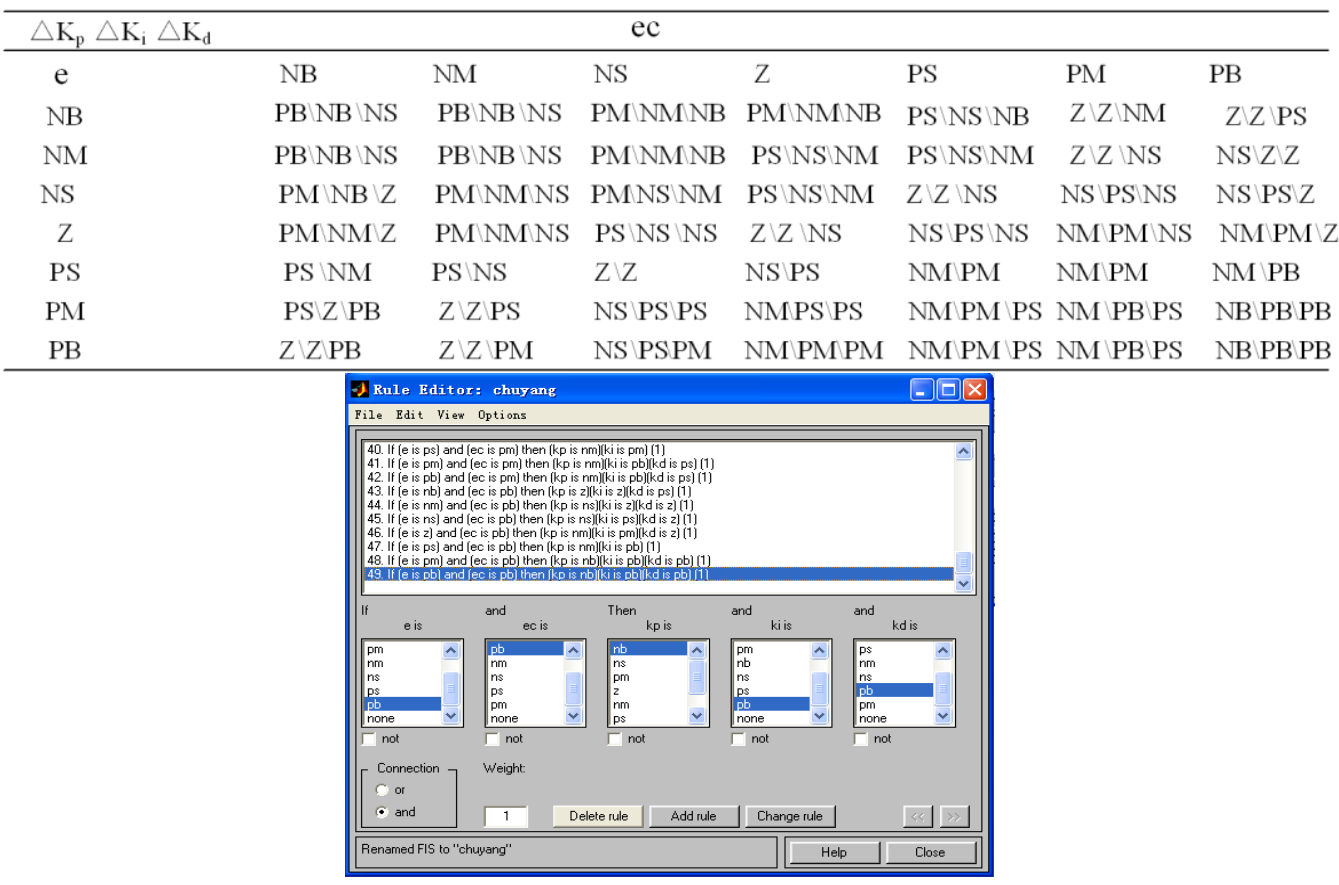

Figure 5. The Fuzzy Principle Design

After the above fuzzy reasoning, fuzzy adaptive,the three adjustment parameters of fuzzy PID controller are the fuzzy quantity, they are to be fuzzy, to obtain the exact amount of three parameters $\mathrm{Kp}, \mathrm{Ki}, \mathrm{Kd}$ for the PID controller. The fuzzy method is the maximum 
average membership degree method, which is used to calculate the average value of the maximum membership value in the fuzzy set as a result of the defuzzification. According to the basic domain and the fuzzy domain the proportion of three output factor is determined:

$$
\mathrm{Up}=1 \mathrm{Ui}=0.1 \mathrm{Ud}=65 \text {. }
$$

The result of three parameters is multiplied by the proportion factor, then the three correction quantity is obtained, and the sum between the initial value and the three parameters is entered to the PID controller.

Fuzzy adaptive tuning PID controller outputs the control signal, the D / A converter converts the digital signal into the analog signal, so the actuating mechanism of the deaerator can obtain temperature control of the deaeretor system.

\section{Simulation and Results of the Control System}

According to the system requirements and parameters design of fuzzy adaptive tuning PID controller, the system simulation is designed in MATLAB, the system simulation block diagram shown in Figure 6.

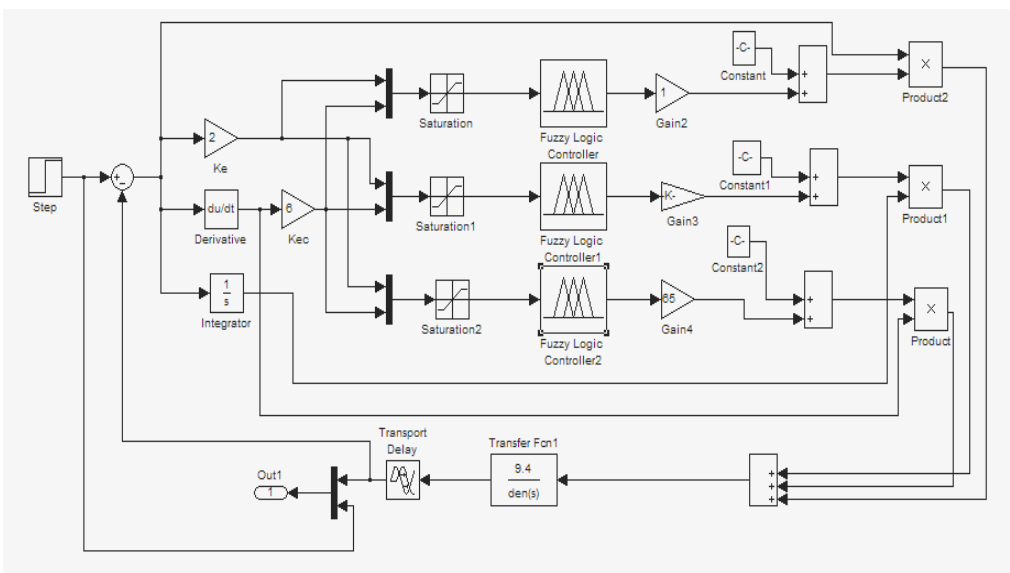

Figure 6. The System Simulation Block Diagram

The simulations are shown in Figure 7 and Figure 8. Figure 7 is for the result of normal PID controller, Figure 8 is for fuzzy adaptive tuning PID control. From the results we can see, the normal PID control has time delay and overshoot, the oscillation is exist at initial time. The fuzzy adaptive PID control has good steady state characteristic, the overshoot is very small, the system has robustness.

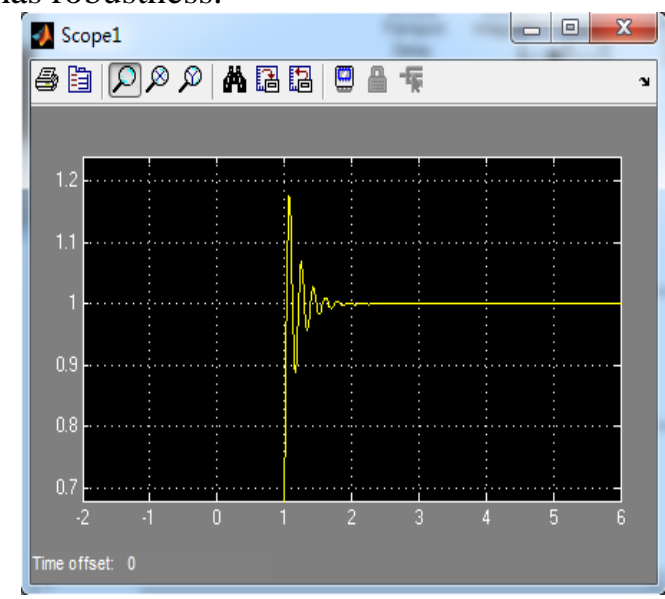

Figure 7. The Result of Normal PID Control 


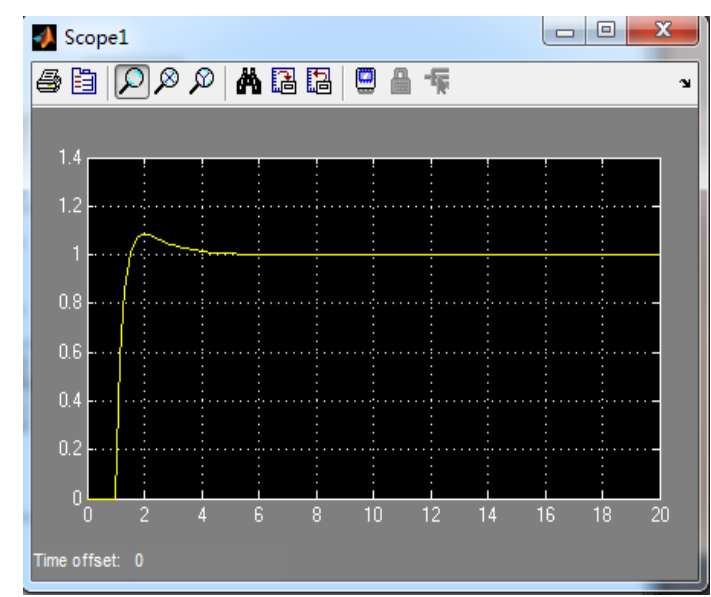

Figure 8. The Result of Fuzzy Adaptive Tuning PID Control

\section{Results and Discussions}

In this paper, a new kind of fuzzy adaptive tuning PID controller is designed,the application is for the deaerator system, from the simulation results we can see:

(1)The fuzzy adaptive PID controller has good dynamic performance than conventional PID control, it has shorter increasing time and adjusting timer, as well as zero steady state overshoot.

(2)In the process of simulation, the fuzzy adaptive PID control can improve the dynamic performance of the control system significantly, and it has good adaptability to the parameters of the controlled system and good robustness.

Results: In this system, as long as the deaerator water tank temperature within the control range $104 \pm 3{ }^{\circ} \mathrm{C}$, the deaerator can achieve good deoxidizing effect. In the design of fuzzy adaptive PID controller, the steady state error is small if we select appropriate quantization factor and scale factor, so as to meet the requirements of control precision.

\section{Acknowledgements}

Thanks for my friend Dr.Lei Jinli. Thanks for the support of Shaanxi Provincial Department of Education Project,the project number is 14JK1049.Thanks for the support of Baoji Science and Technology Bureau Project,the project number is 13KG3-7.Thanks for the support of Baoji University of Arts and Sciences project,the project number is YK1510.

\section{References}

[1]F.Y. Wen, Q. Wang, X.B. Dong, H.L. Ma and G. Tian, “Advanced Materials Research [J]”, vol. 1913, no. 549, (2012), pp. 1032-1036.

[2]R. Guo and W. Wang, "Dual adaptive predictive functional control of boiler deaerator system", Mechanic Automation and Control Engineering (MACE), Second International Conference on 2011 IEEE, (2011).

[3]L. Jinli, "Adaptive Fuzzy PID Control for Boiler Deaerator", Industrial Control and Electronics Engineering (ICICEE), International Conference on 2012 IEEE, (2012).

[4] N.N. Zhou, J.L. Lei and H.C. Zhang, "Application of fuzzy control in deoxidation system [J]”, Transducer and Microsystem Technologies, vol. 26, no. 11, (2007), pp. 105-106.

[5]S.G. Liu, J.M. Wei and Z.C. Zhu, "Intelligent Control Technology [M]", Beijing: China Textile Apparel Press, (2001), pp. 59-102.

[6]W. Wang, "Applied research on fuzzy control technology in the liquid level control system of double couple tanks", Journal of Tianshui Normal University, September, vol. 30, no. 5, (2010), pp. 122-124.

[7]K. Hu, Y. Li and M. Qian, "Research on fluid position system based on fuzzy PID control and industry configuration technology", machine tool \& hydraulics, vol. 37, no. 9, (2009), pp. 150-152.

[8]E. Morteza, A.F. Mohammad and Z. Hadi, “Adaptive fuzzy tuning of PID controllers", Neural Computer and 
Application, vol. 23, no. 1, (2013), pp. S19-S28.

[9] "Spray Deaerator", Kansas City Deaerator Company, Leawood, KS.

[10]E. Kayacan, B.Ulutas and O. Kaynak, "Grey system theory-based models in time series prediction", Expert Systems with Applications, vol. 37, no. 2, (2010), pp. 1784-1789.

[11] S. Prashant, K. Natesan and P. Selvaraj, "Dynamic modeling of steam water system of prototype fast breeder reactor using RELAP code", Annalysis of Nuclear Energy, vol. 68, (2014), pp. 209-219.

[12]T. Spachos and A. Stamatis, "Thermal analysis and optimization of an anaerobic treatment system of whey", Renewable Energy, vol. 36, (2011), pp. 2097-2105.

[13] "Zero-O-Pac Class "S" Deaerating Systems", BFS Industries, LLC , Butner, NC.

[14]A.S. Gimmelberg, 1V.E. Mikhailov and 1V.G.Mikhailov, "1ATMOSPHERIC PRESSURE DEAERATORS FOR HEAT SUPPLY SYSTEMS AT THE SOUTH-WEST POWER PLANT, Power”, Technology and Engineering, vol. 48, no. 1, May (2014).

[15]B.M. Larin and A.B. Larin, "Estimating the Effectiveness of Using Atmospheric Deaerators for Decarbonizing Makeup Water", Thermal Engineering, vol. 62, no. 2, (2015), pp. 154-157.

[16] B. Messner and D. Tilbury, "Controls Tutorials for LabVIEW: PID Control”, (2012), National Instruments. Retrieved from:http://www.ni.com/white-paper/6440/en/

[17] K. Sanders and M.E. Webber, "Evaluating the energy consumed for water use in the United States", Environment Res. Letter, vol. 7, (2012), DOI: 10.1088/1748-9326/7/3/034034.

[18] A.A. Korotkov, "Achieving More Efficient Decarbonization of Water by Means of Atmospheric Pressure Thermal Deaerators", Candidate's Dissertation in Technical Sciences, IGEU, Ivanovo, (2013), Russia.

[19] B.M. Larin and A.B. Larin, "Ionic Equilibriums in Solutions and Natural Waters", IGEU, Ivanovo, (2012), Russian.

[20]S. Wang, S. Yu and F. Zhongxu, "A Method for Controlling a Loading System Based on a Fuzzy PID Controller", vol. 30, no. 1, (2011), p. 166.

\section{Authors}

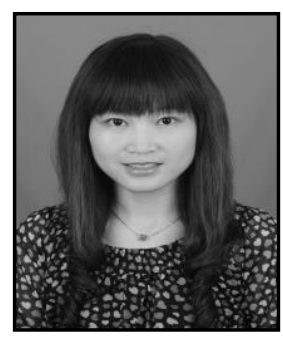

Zhou Nina, master, vice-professor, research direction:intelligent control. 